\title{
Economic component of environmental safety of urban territories with the functioning of thermal energy sources
}

\author{
Alexandr Pashentsev ${ }^{{ }^{*}}$, Anna Garmider ${ }^{2}$, Anna Finogentova ${ }^{2}$, Natalia Shakhova ${ }^{3}$, and Evgenia \\ Statsenko ${ }^{2}$ \\ ${ }^{1}$ The Crimean Federal University n.a. V.I. Vernadsky, Academy of Civil Engineering and \\ Architecture, 298400, Simferopol, Russia \\ ${ }^{2}$ The Crimean Federal University n.a. V.I. Vernadsky, Institute of Economics and Management, \\ 298400, Simferopol, Russia \\ ${ }^{3}$ Russian State University of Justice, Crimean branch, 295006, Simferopol, Russia
}

\begin{abstract}
The essence of the concept of environmental safety of urban areas from the impact of boiler houses is justified on the basis of the synthesis of this definition of domestic scientists. A method for calculation of the indicator of environmental safety of urban areas based on the balance approach, which is based on the comparison of data on anthropogenic pressure exerted by boiler houses on the components of the environment and the ecological capacity of territories, was edveloped. Classification interval estimates of the ecological safety indicator of urban areas have been developed with a brief description, the economic essence of the ecological safety of these territories with a justification of relationship between the environmental, technical, and economic indicators has been proved.
\end{abstract}

\section{Introduction}

At present, the urban area is a complex multicomponent dynamic system with rapidly developing economy sectors, characterized by certain boundaries within which a complex of interconnected buildings, structures, and objects is located, the functioning of which provides human vital activity. The importance of these territories is great for the country's economy, as the enterprises located on them provide a significant contribution to the gross regional product. At the same time, thermal power facilities that produce and distribute thermal energy between consumers throughout the year are of particular importance, which contributes to the life support of the population of these territories. However, along with the positive aspects of these objects, the negative ones are sufficiently large, which result in increased anthropogenic and technogenic load on the environment components, growth of consumption of fuel and energy resources, violation of the processes of ecosystem selfregulation and the integrity of natural features, leading to the progressive development of the process of environmental degradation of the territories. The preservation of the environment is associated with significant material costs, which, under conditions of the limited funds and the need to allocate them to solve the problems of import substitution of the economy, is possible only by the development and implementation of a scientifically

\footnotetext{
*Corresponding author: aleksandr_pashentsev@mail.ru
} 
based set of interconnected multifunctional measures that ensure the equal development of the economy and the environment. At that, the satisfaction of material and spiritual human needs should be carried out with obligatory implementation of the requirements concerning the ecological safety of the urban area, contributing to the update of the means of production and modernization of the domestic production of thermal energy taking into account the most negative impact on the environment. In this regard, ensuring the environmental safety of urban areas from the impact of thermal power facilities is possible if the economic factor that contributes to the restoration of their natural resource potential and minimization the cost of pollution abatement prevails.

\section{Materials and methods}

In the process of research, methods of analysis, abstraction, and comparison were used. The method of analysis, consisting in the decomposition of the research subject into its component parts, is applied in establishing the essential characteristics of the concept of environmental safety of urban areas from the impact of boiler houses. This allowed the team of authors to establish a variety of points of view of scientists, each of which has a specific creative feature, to synthesize them and to offer their own definition. The abstraction method, which consists in mentally distracting from the links, properties, relations, objects and highlighting several significant features of researcher interest, allowed the authors to present an interpretation of the calculation method for assessing the environmental safety of urban areas on the basis of a balance approach by comparing the environmental capacity of the environmental component and anthropogenic pressure. The comparison method, which consists in comparing the calculated values of the studied indicators, allowed to identify and justify the economic component of the environmental safety of urban areas with the presentation of characteristics of classification levels that have passed the goodness-of-fit test.

\section{Results and discussion}

At the present time, the rate of use of natural resource potential and development of the country's economy has led to an increase in social expenses on the reproduction of natural resources and the elimination of emergencies caused by the deterioration of the environmental situation in the regions. This makes it necessary to make significant changes to the state's environmental policy, where special attention should be paid to ensuring the environmental safety of urban areas, as territories of priority development of the country's economy within which $64.72 \%$ of the country's population lives and $85.34 \%$ of industrial enterprises are concentrated [1].

Thermal energy sources provide heat to industrial enterprises, contributing to the functioning of the production process, housing and utilities, services, transport, health, providing comfortable conditions for life. However, when heat is generated, the resulting combustion products transfer the bulk of the heat to the working body of the power plant, and the remaining heat is dissipated into the environment through the chimney. Combustion products released into the atmosphere contain oxides of nitrogen, carbon, sulfur, hydrocarbon, and water vapor in solid, liquid, and gaseous states. The greatest negative impact is caused by heating-production and heating boiler houses that generate heat for heating and hot water supply and operate all year round. Under conditions of constant outside air temperature change the mode of operation of the boiler houses changes, resulting in the increased consumption of raw materials (natural gas, fuel oil, coal), resulting not only in growth of heat production, but also emissions of polluting substances in atmospheric air. Taking into account that the boiler units used in the country differ in a significant time lag of commissioning, temporary specific emission standards for pollutants 
have been developed depending on the period of development of the unit and the fuel used, followed by the calculation of economic damage to the environment and the development of a reconstruction plan. Particular attention is paid to emissions of nitrogen oxide and sulfur, which are characterized by significant relative hazard indicators and a minimum dispersion rate under air masses activity. It is noteworthy that the permissible values of nitrogen oxide emissions by boiler units installed before 01.07.1990 relative to boiler units installed during the period 01.01.1997-31.12.2000 are almost identical when using solid fuel- coal with solid slag removal of $0.21 \mathrm{~kg} / \mathrm{GJ}\left(700 \mathrm{mg} / \mathrm{m}^{3}\right)$, brown coal with solid slag removal of $0.17 \mathrm{~kg} / \mathrm{GJ}\left(450 \mathrm{mg} / \mathrm{m}^{3}\right)$, and presence of a slight discrepancy when using fuel oil $-0.10 \mathrm{~kg} / \mathrm{GJ}\left(290 \mathrm{mg} / \mathrm{m}^{3}\right)$ and $0.086 \mathrm{~kg} / \mathrm{GJ}\left(250 \mathrm{mg} / \mathrm{m}^{3}\right)$, natural gas $0.086 \mathrm{mg} / \mathrm{m}^{3}$ and $0.043 \mathrm{mg} / \mathrm{m}^{3}$. The same type of indicators is typical for sulfur oxide emissions, but with a difference in absolute values that change within the limits - for coal $6.15 \mathrm{~kg} / \mathrm{GJ}$ $\left(570 \mathrm{mg} / \mathrm{m}^{3}\right)$, brown coal $4.98 \mathrm{~kg} / \mathrm{GJ}\left(450 \mathrm{mg} / \mathrm{m}^{3}\right)$, fuel oil $2.93-2.52 \mathrm{~kg} / \mathrm{GJ}(290-250$ $\left.\mathrm{mg} / \mathrm{m}^{3}\right)$, natural gas $2.52-1.26 \mathrm{~kg} / \mathrm{GJ}\left(255-155 \mathrm{mg} / \mathrm{m}^{3}\right)$ [2]. At the same time, almost $43 \%$ of boiler units were installed in the period before 1990[6], which indicates the development of a regulatory resource, the accumulation of negative effects expressed in the occurrence of emergencies, which leads to a decrease in production capacity, an increase in the number of emissions of pollutants. An ambiguous situation is formed with the indicator of specific emission of pollutants by thermal power plants (TPP) per one $\mathrm{kWh}$ of generated energy (table 1).

Table 1. Atmospheric air pollution by thermal power plants using different types of equipment fuel types [7]

\begin{tabular}{|c|c|c|c|c|}
\hline \multirow{2}{*}{ Pollutant } & \multicolumn{4}{|c|}{ Fuel type, $\mathrm{g} / \mathrm{kWh}$} \\
\cline { 2 - 5 } & Coal & Brown coal & Natural gas & Fuel oil \\
\hline $\mathrm{SO}_{2}$ & 6.0 & 7.7 & 7.4 & 0.002 \\
\hline $\mathrm{NO}_{2}$ & 21.0 & 3.4 & 2.4 & 1.9 \\
\hline $\mathrm{CO}_{2}$ & 0.21 & 0.19 & 0.0002 & 0.08 \\
\hline Solid particles & 1.4 & 2.7 & 0.7 & - \\
\hline Total & 28.61 & 13.99 & 10.50 & 1.98 \\
\hline
\end{tabular}

As we can see, the most "dirty" are thermal power plants that use coal as fuel - coal and brown coal, which together with the calorific value indicator predetermined the necessity of using natural gas and fuel oil. As a rule, thermal power plants are located in close vicinity to the cities, and boiler houses are located within the city blocks, having a direct negative impact on the atmospheric air condition. As of 10.11.2019, the economic damage caused by the emissions of pollutants from the boiler houses within the established emission standards is estimated at 36.23 billion rubles, and taking into account the excess of standards 49.34 billion rubles, which carries clear and hidden threats to the environmental condition of the environment and public health. Therefore, it is advisable to proceed from the principle of equal development of society and the environment, aimed at leveling the negative effects of enterprises' activities on the natural environment components with the creation of conditions for economic growth. This determined the interpretation of environmental security from the perspective of compliance with acceptable environmental situation conditions of the safe operation of natural-technogenic systems [9]. In this case, ensuring such a situation involves the use of a set of market tools that directs the activities of enterprises in the production sector, including thermal power plants, within the framework of regulatory impact on the environment with minimal economic damage. In this regard, the economic approach of a number of scientists to the disclosure of the concept of environmental safety of urban areas is quite interesting. So S.I. Velichko understands it as "a set of penalties that contribute to improving the environmental culture of business 
entities and reducing the anthropogenic load on urban areas" [3]. N.M. Vetrova considers environmental security as "a system of economic and institutional measures that allow to neutralize the negative impact of business entities" [4]. A.I. Pashentsev considers environmental security of territories as "a set of economic measures of a proactive nature aimed at reducing the destructive impact of economic entities on the environment" [8]. Then, taking into account the point of view of the above mentioned scientists, we propose the definition of environmental security of urban territories - a state of stabilization that ensures their socio-economic development, provided that anthropogenic pressure does not go beyond the possibilities of self-restoration. In this definition, we can distinguish two components that allow us to propose further the author's approach to calculating the indicator of environmental safety of the city territory from the impact of boiler houses and go to the justification of its economic component. In particular, it is advisable to consider anthropogenic pressure from the perspective of the negative impact of thermal power facilities on the atmospheric air throughout the year, which leads to a change in its quality condition. Then the possibility of self-recovery characterizes the assimilation potential under which we understand the ability of the environment to perceive various anthropogenic impacts on a certain scale without changing its properties in a certain perspective [5]. In this regard, we assess the environmental safety on the basis of a balance approach based on a comparison of anthropogenic pressure from thermal power facilities and the environmental capacity of the component, which is understood as the state of the studied component of the environment relative to changes in environmentally significant parameters. It should be noted that the indicator of the ecological capacity of the environmental component - atmospheric air - is considered from the point of view of restoration under the influence of natural forces of nature. The calculation of the indicator of environmental safety of urban air from the impact of thermal energy sources is carried out according to the methodology, which is advisable to present in the form of a specific algorithm. It consists of five stages. The first one allows to determine the rate of anthropogenic impact on the component, the second - component environmental capacity. The third one is aimed at determining the integral index of environmental safety, the fourth - report on the results of the calculation on the basis of author's classification of the scale of risk the environmental condition of the territory. The fifth stage consists in substantiating the economic component of the environmental safety of urban areas.

The first stage involves the study of the location of the boiler house in order to determine the component of the environment, which is affected by its activities atmospheric air, water resources. However, depending on the type of fuel used, the quantitative composition of pollutants changes, which affects the final value of anthropogenic pressure.

$$
P_{l}=\sum W_{i} \cdot t_{1} \cdot n ;
$$

where $\sum \mathrm{W}_{\mathrm{i}}$ is the total amount of emissions of $\mathrm{i}$-th pollutant by the boiler house in the air, $\mathrm{kg}$ /day; $\mathrm{t}_{1}-$ duration of the boiler house operation during the year, day; $\mathrm{n}-$ number of boiler houses, pcs.

$$
P_{2}=W_{j} \cdot K_{l} ;
$$

where $\sum \mathrm{W}_{\mathrm{j}}$ is the total volume of untreated waste water discharge from the boiler house during the year to water sources, $\mathrm{m}^{3} /$ year; $\mathrm{K}_{1}$ - the dilution coefficient of untreated waste water from a natural water source.

$$
P_{3}=W_{r} \cdot K_{2} \cdot K_{3} ;
$$

where $\sum \mathrm{W}_{\mathrm{j}}$, the sum of the discharge of insufficiently treated waste water by boiler house during the year to water sources $\mathrm{m}^{3} /$ year; $\mathrm{K}_{1}$ - coefficient of the wastewater treatment 
equipment of the boiler house; $\mathrm{K}_{3}$ - coefficient of dilution of insufficiently treated wastewater of boiler house by natural water source.

Then the total indicator of anthropogenic pressure of the boiler house on the environment can be determined:

$$
P=P_{1}+P_{2}+P_{3}
$$

The second stage allows to calculate the environmental capacity of the component based on the definition

of oxygen recovery indicator, as a substance that provides the vital activity of living organisms.

$$
M_{1}=F_{1} \cdot m_{1} \cdot K_{3}
$$

where $F_{1}$ - area of urban territory occupied by forest stands in the close vicinity to the boiler house, $\mathrm{km}^{2} ; \mathrm{m}_{1}$ - coefficient that takes into account the rate of oxygen reproduction depending on the type of forest stands; $\mathrm{K}_{3}$ - standard indicator of oxygen reproduction depending on the type of forest stands, $\mathrm{t} / \mathrm{km}^{2}$.

$$
M_{2}=F_{2} \cdot m_{1} \cdot K_{4}
$$

where $\mathrm{F}_{2}$ - area of urban territory occupied by water sources in the close vicinity to the boiler house, $\mathrm{km}^{2} ; \mathrm{m}_{2}$ - coefficient that takes into account the rate of oxygen reproduction by a water source; $K_{3}$ - standard indicator of oxygen renewal by a water source, $t / \mathrm{km}^{2}$.

If several water sources (river, pond, lake) are located in the area of operation of the boiler house, then the indicator of oxygen renewal must be taken into account for each source. In this case, the amount of reproduced oxygen from water sources is determined by the amount of reproduction for each source. Then the summary indicator of the ecological capacity of the urban area in the zone of influence of the source of thermal energy is determined:

$$
M=M_{1}+M_{2}
$$

where $\mathrm{M}_{1}, \mathrm{M}_{2}$ - respectively, the amount of oxygen produced by atmospheric air, water source.

Knowing the total values of anthropogenic pressure of a thermal energy source on the environment and environmental capacity, it is possible to determine the indicator of environmental safety of urban territories, which the third stage provides for:

$$
K=M / P
$$

This indicator is complex in nature, since it provides for the calculation of individual indicators based on an objective statistical database on the emissions of pollutants from boiler houses for thermal energy generation and the area occupied by forest and water resources that provide oxygen reproduction. However, the presence of this indicator implies the justification of the conclusion about the real state of urban territories that are directly affected by the source of pollution. In our opinion, this can be done by having interval estimates with detailed characteristic. In this case, the definition of interval estimates is possible with full consideration of the quantitative composition of the data used in the calculation process of the environmental safety indicator, using the mathematical expression of Sturgess. It should be noted that depending on the complexity and importance of the problem being solved, the value of the confidence probability changes, which affects the determination of the length of the interval and the number of intervals. However, the higher the confidence level value, the shorter the length of the interval and the greater their 
number, which allows to develop a more detailed characteristic of the interval assessment of the environmental safety of urban territories. The calculation adopted a confidence level of 0.95 , which allowed to obtain five interval estimates:

- 1.0,00-0,191 - critical - implementation of the environmental audit system of the polluting enterprise;

$-2.0,192-0,383$ - low - implementation of an environmental monitoring system for the implementation of a program for pollutant emissions regulation;

$-3.0,384-0,575$ - medium - implementation of the environmental quality management program;

$-4.0,576-0,767$ - favorable- conducting an environmental audit to prevent an increase in pollutant emissions;

$-5.0,68-0,959$ - high - equilibrium ecological state of the city territory in the zone of boiler house impact.

Calculations can be performed for several environmental components under consideration and an aggregate indicator of environmental safety can be obtained, as well as for each of them, which will allow comparing the results obtained and identifying the component most exposed to the negative impact of the boiler house.

The use of these interval estimates is aimed at determining the actual state of the environment from the impact of boiler houses and justification of measures for the reconstruction of thermal source equipment, which will allow them to be differentiated by the degree of priority of these measures. When positioning boiler houses by environmental safety assessment, it is necessary to assess its economic component, which can be done using indicators of economic damage $\left(E_{d}\right)$ and the cost of boiler equipment $\left(C_{b}\right)$ to be replaced due to the development of a regulatory resource, as well as a low level of technical condition, which led to an increase in failures and increased emissions of pollutants. In this case, it is necessary to link the environmental indicators with the technical ones (availability coefficient $\mathrm{C}_{\mathrm{a}}$, physical wear and tear coefficient $\mathrm{C}_{\mathrm{w}}$, useful performance coefficient of boiler equipment $\mathrm{C}_{\mathrm{up}}$ ) and the above-mentioned economic ones. The use of economic indicators is important in justifying the decision regarding the operation of the boiler house. In particular, economic damage characterizes the actual situation of the boiler house's impact on the environment in the current period of time. The indicator of the cost of the boiler house equipment to be replaced characterizes the objective need to improve the situation by carrying out its reconstruction. In this regard, the methodological approach was tested on the example of the cities of Simferopol, Kerch, and Yevpatoria of the Republic of Crimea, with verification of the calculation results for adequacy (table 2).

Table 2. Economic component of environmental safety of urban territories from the impact of boiler houses

\begin{tabular}{|c|c|c|c|c|c|c|c|c|}
\hline Republic & City & $\begin{array}{c}\text { Ecological } \\
\text { safety }\end{array}$ & \multicolumn{2}{|c|}{ Technical indicators } & \multicolumn{2}{|c|}{$\begin{array}{c}\text { Economic } \\
\text { indicators }\end{array}$} & \multirow{2}{*}{$\begin{array}{c}\text { Fisher } \\
\text { criterion }\end{array}$} \\
\cline { 3 - 8 } & $\mathrm{C}$ & $\mathrm{C}_{\mathrm{a}}$ & $\mathrm{C}_{\mathrm{w}}$ & $\mathrm{C}_{\mathrm{up}}$ & $\begin{array}{c}\mathrm{E}_{\mathrm{d}}, \\
\text { million } \\
\text { rubles }\end{array}$ & $\begin{array}{c}\mathrm{C}_{\mathrm{b}}, \\
\text { million } \\
\text { rubles }\end{array}$ & \\
\hline Crimea & Kerch & 0.56 & 0.54 & 0.73 & 0.34 & 82.32 & 56.89 & $0.881>0.10$ \\
\cline { 2 - 9 } & Simferopol & 0.49 & 0.48 & 0.81 & 0.39 & 96.04 & 62.21 & $0.912>0.10$ \\
\cline { 2 - 8 } & Yevpatoria & 0.59 & 0.62 & 0.64 & 0.48 & 69.02 & 43.77 & $0.799>0.10$ \\
\hline
\end{tabular}

As can be seen from table 2 the indicator of environmental safety of urban territories belongs to the average group, which requires the development and implementation of an environmental quality management program for facilities that produce thermal energy. At the same time, the technical condition of boiler equipment is low - the coefficient of physical wear is $0.64-0.81$, the efficiency of boiler units is $0.34-0.48$, which led to a 
minimization of the readiness coefficient of $0.48-0.62$. The economic damage to urban territories from pollutants emitted by boilers is estimated at 69.02-96.04 million rubles, which indicates the excess of pollutant emission standards. The analysis of these data indicates the presence of a relationship between them. I.e. the low technical condition of the boiler houses equipment leads to a decrease in the efficiency, contributing to an increase in pollutant emissions and a decrease in environmental safety, which is reflected in an increase in the rate of economic damage.

\section{Conclusions}

The economic component of the environmental safety of urban territories from the impact of boiler houses is justified on the basis of comparison of a group of environmental, technical, and economic indicators. Approbation of proposed method with validation of the results obtained on the adequacy of evidence of the objectivity of judgments of the authors about the existence of a direct link between the low level of technical condition of boiler equipment, low level of environmental security of urban territories and a high level of economic damage and cost of the equipment of boiler houses to be replaced.

\section{References}

1. P. A. Anisimov, Economic ecology, 288 (Piter, city of Saint Petersburg, 2018)

2. O. N. Bragina, Standards for specific emissions of pollutants into the atmosphere from TPP boiler plants, JSC VTI. E.120-bal.ru/doc/6521/index.html

3. P. T. Velichko, Economic tools for ensuring environmental safety, 179 (Lutsk, Scientific world, 2016)

4. N. Vetrova, The assessment of waters ecological state of the Crimea coastal near highrise construction zones, E3S Web of conferences 33, 02051 (2018) HRC 2017/ https://doi/ org/10/015/e3sconf/20183302051

5. A.E. Vorobyov, Fundamentals of environmental management, 544 (Rostov-on-don, Phoenix, 2006)

6. A. T. Voznesensky, Economic ecology, 248 (Novosibirsk, Svityaz, 2018)

7. V.V. Glukhov, Economic foundations of ecology: textbook, 383 (Piter, St. Petersburg, 2003)

8. A. I. Pashentsev, Mechanism of preventive environment protection, 289 (Simferopol, DIAYPI, 2011)

9. N. Stacenko, N. Oshovskaya, A. Finogentova, A. Efremova, Toolkit for assessing and managing a balanced environmental management system, 2nd International conference on education science and social development (essd 2019), Series: advances in social science, education and humanities research (China, 2019) 